\title{
Impact of neutrophil-to-lymphocyte ratio on periprocedural myocardial infarction in patients undergoing non-urgent percutaneous coronary revascularisation
}

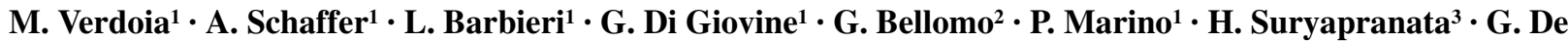 \\ Luca $^{1}$
}

Published online: 8 June 2016

(C) The Author(s) 2016. This article is available at SpringerLink with Open Access.

\begin{abstract}
Background Pro-thrombotic conditions importantly influence myocardial perfusion and procedural results after percutaneous coronary intervention (PCI). The neutrophil-tolymphocyte ratio (NLR) has emerged as a predictor of cardiovascular events and of long-term prognosis, especially in ST-elevation myocardial infarction patients undergoing primary PCI. The aim of our study was to evaluate the role of NLR on periprocedural myocardial infarction (MI) in patients undergoing non-urgent PCI.

Methods In a consecutive cohort of 1542 patients undergoing PCI, myonecrosis biomarkers were determined at 6, 12, 24 and 48 hours post-procedure. Patients were divided into quintiles according to NLR values. Periprocedural myonecrosis was defined as a troponin I increase of 3 times the upper limit of normal or as $50 \%$ of an elevated baseline value, whereas periprocedural MI was defined as a CK-MB increase of 3 times the upper limit of normal or $50 \%$ of baseline.

Results Higher NLR was related to age, established risk factors and cardiovascular history. NLR was associated with severe coronary artery disease $(p=0.009)$, tighter
\end{abstract}

On behalf of the Novara Atherosclerosis Study Group (NAS)

G. De Luca

giuseppe.deluca@maggioreosp.novara.it

1 Division of Cardiology, Azienda Ospedaliera-Universitaria Maggiore della Carità, Eastern Piedmont University, Novara, Italy

2 Division of Clinical Chemistry, Azienda Ospedaliera-Universitaria Maggiore della Carità, Eastern Piedmont University, Novara, Italy

3 Division of Cardiology, UMC St Radboud, Nijmegen, The Netherlands stenosis $(p<0.001)$, coronary calcifications $(p=0.005)$, intracoronary thrombus or thrombectomy use $(p<0.001)$, TIMI flow pre- and post-PCI $(p<0.001)$, and inversely to restenosis $(p=0.04)$ and use of a drug-eluting stent $(p=$ $0.001)$. NLR did not influence the occurrence of myonecrosis $(p=0.75$; adjusted OR $(95 \% \mathrm{CI})=0.99(0.63-1.54)$, $p=0.96$ ), but was associated with a higher occurrence of periprocedural MI, even after correction for baseline differences $(p=0.03$; adjusted OR $(95 \% \mathrm{CI})=1.33(1.02-2.3)$, $p=0.02$ ), with NLR $\geq 3$ best predicting the risk of periprocedural MI at the receiver operating characteristic curve analysis.

Conclusion In patients undergoing non-urgent PCI, a higher NLR increases the risk of periprocedural MI, especially for values $\geq 3$.

Keywords Neutrophil/lymphocyte ratio - White blood cells $\cdot$ PCI $\cdot$ Periprocedural myocardial infarction

\section{Background}

Technological improvements and the introduction of new, more potent, antithrombotic therapies [1-3] have allowed an escalation in the complexity of percutaneous coronary interventions (PCI), therefore enhancing the risk of periprocedural complications $[4,5]$.

In fact, many patients still suffer a periprocedural myocardial infarction (MI), especially as a consequence of flowlimiting complications, although a myocardial injury can also occur silently, due to the formation of leukocyte and platelet plugs in the microvascular circulation, preventing myocardial perfusion and potentially negatively influencing the prognosis [4-6]. Thus, white blood cells and inflamma- 


\section{Advertisement placed here.}

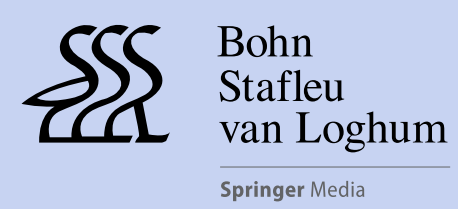

Houten 2016 


\section{Advertisement placed here.}

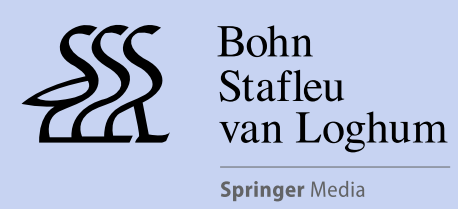

Houten 2016 


\section{Advertisement placed here.}

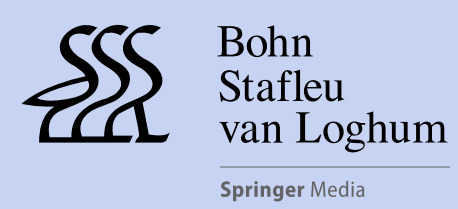

Houten 2016 


\section{Advertisement placed here.}

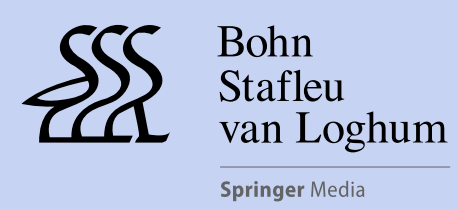

Houten 2016 


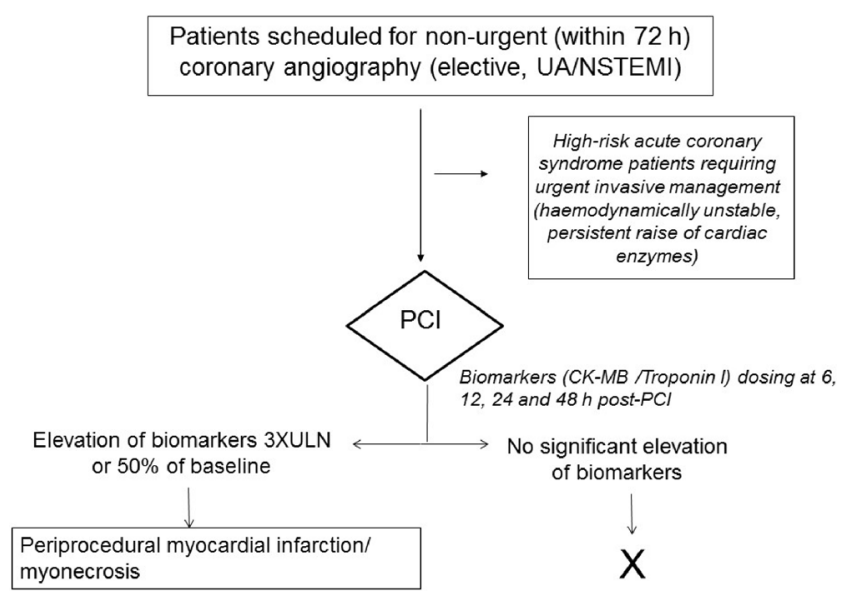

Fig. 1 Flow chart for patient inclusion and study procedures

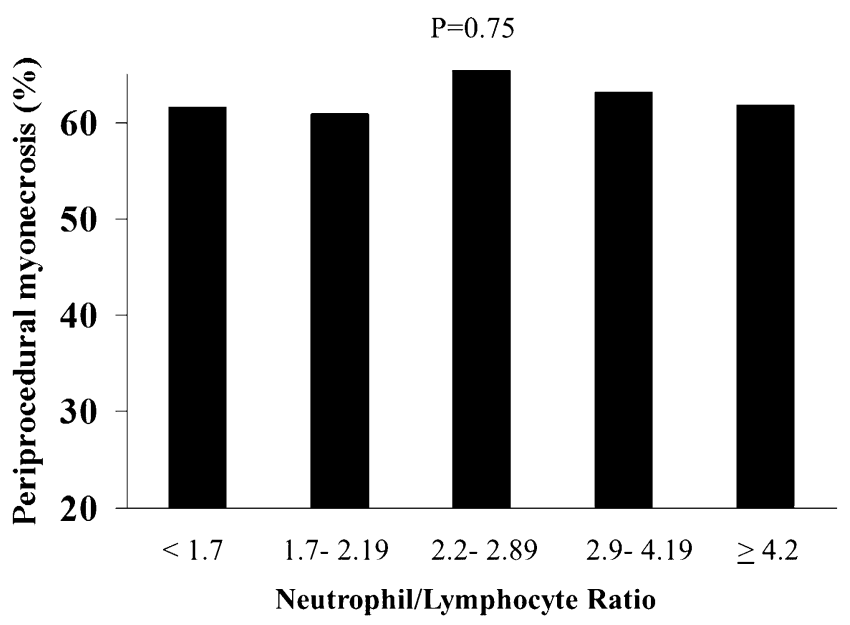

Fig. 3 Bar graph showing the prevalence of periprocedural myonecrosis according to neutrophil to lymphocyte ratio (NLR) quintiles values

tory status can be involved in these events, enhancing prothrombotic response and platelet reactivity.

The neutrophil-to-lymphocyte ratio (NLR) has recently emerged among the markers of inflammation, being an inexpensive, easy to obtain parameter, which can improve the risk stratification of patients with cardiovascular disease [7]. In fact, it has been associated with arterial stiffness and with the indicators of the extent of coronary artery disease $[8,9]$, and moreover with thrombus formation in acute coronary syndromes [10]. In these settings NLR has been suggested to influence short-term and long-term outcome, especially in patients with ST-segment elevation myocardial infarction (STEMI) undergoing primary PCI $[11,12]$. However, no study has so far evaluated its impact in patients undergoing non-urgent percutaneous coronary revascularization. The aim of our study was, then, to assess whether NLR can influence the risk of periprocedural MI in patients undergoing non-urgent PCI.

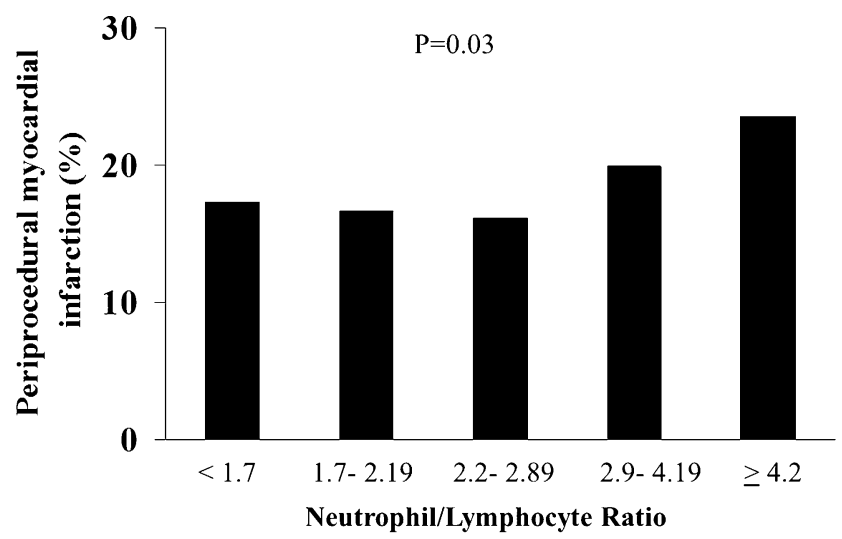

Fig. 2 Bar graph showing the prevalence of periprocedural myocardial infarction according to neutrophil to lymphocyte ratio (NLR) quintiles values

\section{Methods}

We included patients undergoing coronary angioplasty at Ospedale "Maggiore della Carità" from May 2007 to January 2013 for both elective indications or acute coronary syndromes (unstable angina/NSTEMI). NSTEMI patients were defined by the presence of chest pain and cardiac biomarkers elevation above the upper limit of normality $(0.04 \mu \mathrm{g} / \mathrm{l}$ for troponin I and $5.00 \mu \mathrm{g} / \mathrm{l}$ for CK-MB, respectively) and underwent elective coronary angiography after pharmacological stabilisation, but not STEMI and unstable patients requiring urgent angioplasty.

Diabetes mellitus was defined as one of the following: 1) previous diagnosis, 2) specific treatment of diabetes (oral or insulin), 3) fasting glycaemia $>126 \mathrm{mg} / \mathrm{dl}$ in at least two repeated determinations, 4) or HbA1c $>6.5 \%$. Hypertension was defined as a systolic pressure $>140 \mathrm{mmHg}$ and/or diastolic pressure $>90 \mathrm{mmHg}$ or if the individual was taking antihypertensive medications [13].

The study was approved by our local ethics committee. In accordance with the guidelines, all patients received a bolus of an antiplatelet adenosine diphosphate antagonist at the time of hospitalisation or before angioplasty. Patients were clinically followed up to hospital discharge.

\section{Biochemical measurements}

Blood samples were drawn at admission (following a fasting period of 12 hours) in patients undergoing coronary angiography for elective or acute indications. Glucose, creatinine, HbA1c and lipid profile were determined by standard methods. The total and differential white blood cell count was measured in a blood sample collected in tripotassium EDTA $(7.2 \mathrm{mg})$ tubes. These blood samples were analysed within 2 hours of venepuncture by an au- 


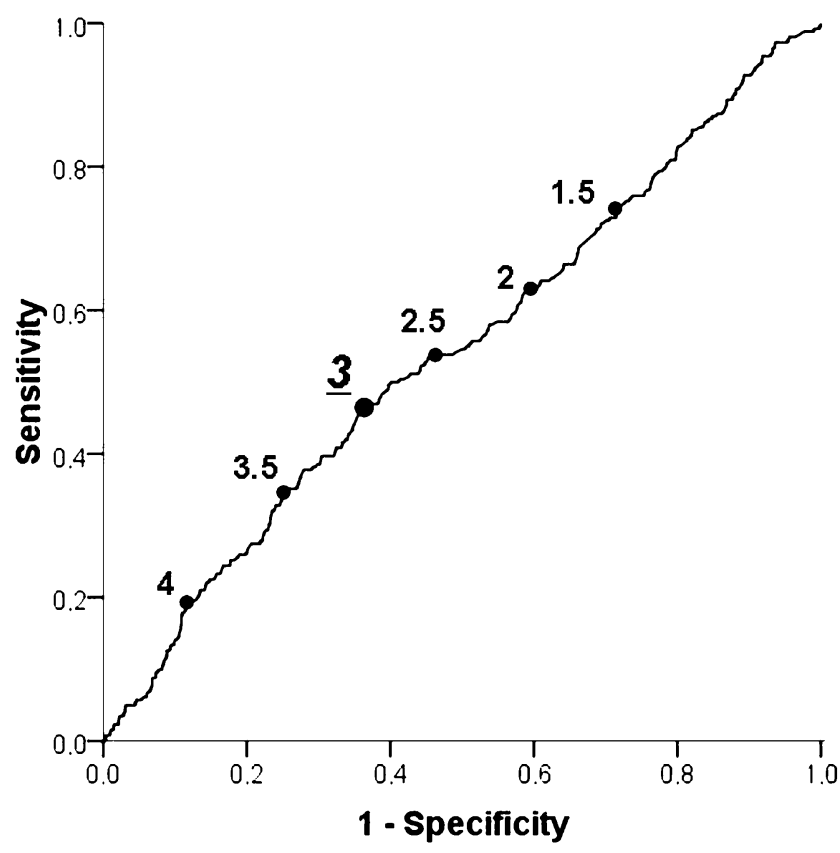

Fig. 4 Receiver-operating characteristic (ROC) curve for the neutrophil to lymphocyte ratio (NLR) values in the prediction of periprocedural myocardial infarction

tomatic blood counter (Sysmex XE-2100) used for whole blood analysis. The neutrophil/lymphocyte ratio was measured for each patient. Cardiac biomarkers (troponin I and CK-MB) were measured at baseline, before coronary revascularization, and later at $6,12,24$ and 48 hours after PCI.

\section{Coronary angiography and PCI}

Coronary angiography was routinely performed by the Judkins technique using 6-French catheters. Quantitative coronary angiography was performed by experienced interventional cardiologists using an automatic edge-detection system (Siemens Acom Quantcor QCA, Erlangen, Germany) [14]. Coronary angioplasty was performed with standard techniques. All patients received a bolus of unfractionated heparin during coronary angiography $(80 \mathrm{U} / \mathrm{kg})$ and if needed additional heparin was administered during the procedure according to the activated clotting time. An oral loading dose of an adenosine diphosphate antagonist (600 mg clopidogrel or $180 \mathrm{mg}$ ticagrelor) was given before PCI, if the patient had not already been pre-treated with oral dual-antiplatelet therapy.

Use of stents, type of stents and stent implantation techniques, as well as the use of directional or rotational atherectomy, intravascular ultrasound, and glycoprotein IIb/ IIIa inhibitors, was left to the discretion of the operators.

\section{Study endpoints}

The primary study endpoint was periprocedural MI defined as CK-MB mass value $\geq 3$ times the upper limit normal or an increase of $50 \%$ of baseline value if already elevated, but stable or falling, at the time of the procedure. The secondary study endpoint was a periprocedural increase in troponin $\mathrm{I} \geq 3$ times the upper limit normal or an increase of $50 \%$ of the preprocedural value, if $>0.04 \mathrm{ng} / \mathrm{ml}$. In addition, the most recent definition of periprocedural MI as a troponin I increase of 5 times the upper limit normal or $20 \%$ of a baseline elevated value was also used.

\section{Statistical analysis}

Statistical analysis was performed using the SPSS 17.0 statistical package. Patients were divided into quintiles according to NLR values $(<1.7 ; 1.7-2.19 ; 2.20-2.89 ; 2.9-4.19$; $\geq 4.2$ ). Continuous data are expressed as mean \pm SD and categorical data as percentages. Analysis of variance and the chi-square test (or Fisher's test) were used for continuous and categorical variables, respectively. Multiple logistic regression analysis was performed to evaluate the relationship between NLR and periprocedural myocardial necrosis or infarction, after correction for clinical and angiographic significant differences, which were entered in the model in block. Receiver-operating characteristic (ROC) curve analysis was performed to identify the best predicting value for periprocedural MI.

\section{Results}

Our population consisted of 1542 patients; 1084 were diagnosed with acute coronary syndrome, while 458 were stable patients scheduled for PCI. The flowchart for patient selection is shown in Fig. 1.

As shown in Tab. 1, higher NLR was related to age ( $p$ $<0.001)$, hypertension $(p=0.02)$, hypercholesterolaemia $(p<0.001)$, acute coronary syndrome at admission $(p=$ $0.003)$, use of diuretics $(p=0.001)$, glycaemia, creatinine, fibrinogen, C-reactive protein and white blood cell count ( $p$ $<0.001)$, and inversely with smoking $(p=0.001)$, previous PCI $(<0.001)$, treatment with beta-blockers, statins and acetylsalicylic acid and haemoglobin values $(p<0.001)$.

Tab. 2 displays the main angiographic characteristics and procedural features. NLR was associated with more severe coronary artery disease $(p=0.009)$, tighter stenosis $(p$ $<0.001)$, coronary calcifications $(p=0.005)$, intracoronary thrombus or need for thrombectomy ( $p<0.001)$, TIMI flow pre- and post-PCI $(p<0.001)$, and inversely with restenosis $(p=0.04)$ and use of drug-eluting stent (DES) $(p=0.001)$. 


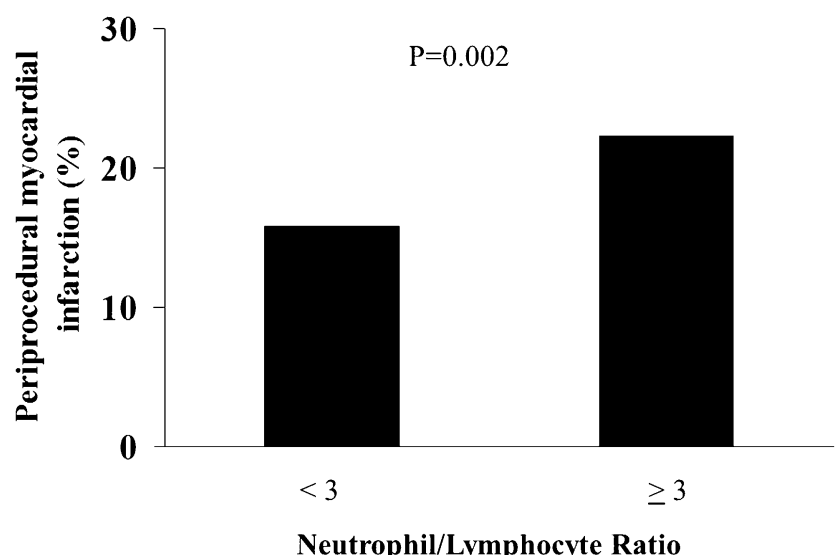

Fig. 5 Bar graph showing the prevalence of periprocedural myocardial infarction in patients with neutrophil to lymphocyte ratio (NLR) $\geq 3$

NLR was associated to a higher occurrence of periprocedural MI (17.3 vs 16.6 vs 14.1 vs 19.9 vs $23.5 \%, p=$ 0.03 , OR $(95 \% \mathrm{CI})=1.11(1.01-1.22), p=0.03)$, as displayed in Fig. 2, but did not influence the occurrence of myonecrosis (61.5 vs 60.9 vs 66.6 vs 63.2 vs $61.8 \%, p=$ 0.75; OR (95\% CI) = 1.01 (0.94-1.09), $p=0.75$; Fig. 3).

The results were maintained after correction for baseline differences (age, hypertension, hypercholesterolaemia, acute coronary syndrome, treatment with beta-blockers, statins, acetylsalicylic acid and diuretics, glycaemia, creatinine, fibrinogen, C-reactive protein, haemoglobin, white blood cell count, smoking, previous PCI, severity of coronary artery disease, \% stenosis, coronary calcifications, intracoronary thrombus, thrombectomy, TIMI flow preand post-PCI, restenosis and use of DES), for both myonecrosis $($ adjusted OR $(95 \% \mathrm{CI})=0.99(0.63-1.54), p=$ $0.96)$, and periprocedural MI (adjusted OR $(95 \% \mathrm{CI})=$ $1.33(1.02-2.3), p=0.02)$ and also when considering NLR as a continuous variable (myonecrosis: adjusted OR $(95 \% \mathrm{CI})=1.01(0.97-1.06), p=0.63$; periprocedural MI: adjusted OR $(95 \% \mathrm{CI})=1.05(1.001-1.10), p=0.05)$.

At ROC curve analysis, NLR $\geq 3$ proved to have the best predictive value for the risk of periprocedural MI (AUC $0.544, p=0.03$, Fig. 4 ), and in fact, when dividing our patients for NLR $<$ or $\geq 3$, a higher rate of periprocedural MI was found in patients with elevated NLR (15.8 vs $22.3 \%$, $p=0.02$, adjusted OR $(95 \% \mathrm{CI})=1.39(1.03-1.88), p=$ 0.03, as shown in Fig. 5).

Analogous results were achieved when separately considering acute coronary syndrome $(n=1084)$ and stable patients $(n=458)$. In fact, among acute patients, an increased rate of periprocedural MI was observed for NLR $\geq 3$ (periprocedural MI: 28.1 vs $20.7 \%, p=0.03$; adjusted OR $(95 \% \mathrm{CI})=1.53(1.01-2.3), p=0.04$; myonecrosis: 57.6 vs $56.6 \%, p=0.82$; adjusted OR $(95 \% \mathrm{CI})=1.05$ $(0.67-1.63), p=0.84)$. On the contrary, among patients with stable coronary artery disease, we confirmed a similar occurrence of myonecrosis according to NLR $<$ or $\geq 3$ $(70.3$ vs $67.5 \%, p=0.48$; adjusted $\mathrm{OR}(95 \% \mathrm{CI})=1.21$ $(0.63-2.31), p=0.57)$ whereas we observed an absolute increase in the rate of periprocedural MI (19.2 vs $13.7 \%, p=$ 0.22 ), although not reaching statistical significance at multivariate analysis (adjusted OR $(95 \% \mathrm{CI})=2.2(0.94-4.9)$, $p=0.07$ ).

Results did not change when applying a more recent definition of periprocedural MI (troponin I $>5 \mathrm{x}$ upper limit normal or $20 \%$ of baseline value), with a trend for higher periprocedural myocardial injury in patients with NLR $\geq 3$ $(67.5$ vs $64.6 \%, p=0.21$; adjusted OR $(95 \% \mathrm{CI})=1.21$ $(0.92-1.58), p=0.16)$.

\section{Discussion}

This is the first study to evaluate the role of NLR on periprocedural MI in patients undergoing non-urgent PCI. Our main finding is that higher NLR increases the risk of periprocedural MI; this applies especially for NLR $\geq 3$.

In the last decades, various efforts have been made to improve the outcome in patients with coronary artery disease, by shortening the time to treatment in acute myocardial infarction and introducing new techniques for the percutaneous treatment of more and more complex lesions [15-17]. However, despite the great reduction in mortality observed, especially in the setting of STEMI, suboptimal results have still been obtained in certain subsets of high-risk patients [18-21]. Therefore, in recent years, great efforts have been focused on the prevention of periprocedural complications. In effect, periprocedural myocardial injury has been shown by MRI studies to occur in the majority of PCI procedures [22], thus requiring the identification of new biomarkers to improve risk stratification.

Inflammation is a well-established risk factor for coronary artery disease, playing a role in the progression of atherosclerosis and regulating the process leading to the "instabilisation" of a plaque, and then to an acute ischaemic event [23]. Moreover, inflammatory response has been strictly linked to an enhanced pro-thrombotic status, by increasing the circulating levels of fibrinogen and other coagulative factors and by enhancing platelet reactivity through reactive oxygen species, cytokines and other mediators [24]. Many studies have evaluated the prognostic role of inflammatory biomarkers in cardiovascular disease, with contrasting results [25]. Initial studies showed that an elevated total white blood cell count was associated with increased mortality and worse outcomes after acute MI, and mainly for patients with higher neutrophil counts [26]. More recently, attention shifted to the NLR, combining the effects of the nonspecific inflammatory response, mediated by neu- 
Tab. 1 Clinical and demographic characteristics neutrophil/lymphocyte ratio quintiles

\begin{tabular}{|c|c|c|c|c|c|c|}
\hline Baseline clinical characteristics & $\begin{array}{l}\text { I quintile } \\
n=309\end{array}$ & $\begin{array}{l}\text { II quintile } \\
n=297\end{array}$ & $\begin{array}{l}\text { III quintile } \\
n=320\end{array}$ & $\begin{array}{l}\text { IV quintile } \\
n=307\end{array}$ & $\begin{array}{l}\text { V quintile } \\
n=309\end{array}$ & $p$ value \\
\hline Age (mean \pm SD) & $64.7 \pm 10.8$ & $66.9 \pm 10.8$ & $66.6 \pm 11.3$ & $69.2 \pm 10.6$ & $70.5 \pm 11.3$ & $<0.001$ \\
\hline Male sex $(\%)$ & 76 & 76.6 & 79 & 77.2 & 73.7 & 0.54 \\
\hline Arterial hypertension (\%) & 70.4 & 74.9 & 75.2 & 70.1 & 72.4 & 0.02 \\
\hline Diabetes mellitus (\%) & 38.6 & 32.6 & 38.8 & 36.3 & 35.3 & 0.68 \\
\hline Hypercholesterolaemia (\%) & 64.6 & 63 & 63.5 & 53.8 & 46.8 & $<0.001$ \\
\hline Smokers $(\%)$ & & & & & & 0.001 \\
\hline Active smokers & 26.9 & 26.2 & 26.3 & 23.6 & 20.5 & \\
\hline Previous smoker & 27.7 & 27 & 28.6 & 19.9 & 21.5 & \\
\hline Renal failure (\%) & 20.3 & 22.8 & 21.9 & 23.2 & 25.8 & 0.09 \\
\hline History of MI (\%) & 27.2 & 29.1 & 27.2 & 24.5 & 23.6 & 0.1 \\
\hline Previous PCI (\%) & 35.4 & 33.3 & 30 & 27 & 24.6 & $<0.001$ \\
\hline Previous CABG (\%) & 11.6 & 15.4 & 13.7 & 14.8 & 12.6 & 0.82 \\
\hline Indication to angiography (\%) & & & & & & 0.003 \\
\hline Stable angina & 32.4 & 30.1 & 31.4 & 19.4 & 8.9 & \\
\hline Acute coronary syndrome & 63.2 & 62.7 & 62 & 76.9 & 84.6 & \\
\hline LV dysfunction/Arrhythmia & 4.4 & 7.1 & 6.6 & 3.8 & 6.5 & \\
\hline \multicolumn{7}{|l|}{ Therapy at admission } \\
\hline ACE inhibitors (\%) & 44.1 & 42.9 & 44.4 & 46.2 & 39.6 & 0.5 \\
\hline $\operatorname{ARB}(\%)$ & 23.4 & 24.7 & 26.4 & 23.1 & 22 & 0.55 \\
\hline Beta blockers $(\%)$ & 65.8 & 63.2 & 59 & 60.1 & 46.9 & $<0.001$ \\
\hline Nitrates (\%) & 40.8 & 44.8 & 49.1 & 49.3 & 33.2 & 0.23 \\
\hline Calcium antagonists $(\%)$ & 24.3 & 25.2 & 28.6 & 22.6 & 21.5 & 0.30 \\
\hline Diuretics $(\%)$ & 26.8 & 23.8 & 32.2 & 33 & 36.3 & 0.001 \\
\hline Statins (\%) & 68.8 & 63.9 & 61.8 & 57.4 & 40.9 & $<0.001$ \\
\hline Acetylsalicylic acid (\%) & 74.9 & 73.6 & 71.5 & 63.5 & 51.6 & $<0.001$ \\
\hline Clopidogrel (\%) & 29 & 34 & 30.7 & 35.6 & 22.4 & 0.17 \\
\hline \multicolumn{7}{|l|}{ Main chemistry } \\
\hline Glycaemia $(\mathrm{mg} / \mathrm{dl} \pm \mathrm{SD})$ & $128.3 \pm 50.7$ & $122.2 \pm 46.8$ & $129.7 \pm 58$ & $131.9 \pm 49.6$ & $148.4 \pm 65.5$ & $<0.001$ \\
\hline Creatinine $(\mathrm{mg} / \mathrm{dl} \pm \mathrm{SD})$ & $0.99 \pm 0.56$ & $1.06 \pm 0.67$ & $1.11 \pm 0.73$ & $1.09 \pm 0.67$ & $1.33 \pm 1.17$ & $<0.001$ \\
\hline Platelets $\left(10^{3} / \mathrm{ml}\right.$; mean $\left.\pm \mathrm{SD}\right)$ & $210.6 \pm 58$ & $213.3 \pm 53$ & $210.6 \pm 58.8$ & $213.4 \pm 63.5$ & $217.7 \pm 82.9$ & 0.52 \\
\hline Haemoglobin $(\mathrm{g} / \mathrm{d} \pm \mathrm{SD} 1)$ & $13.7 \pm 1.6$ & $13.7 \pm 1.5$ & $13.5 \pm 1.7$ & $13.2 \pm 1.8$ & $12.9 \pm 2$ & $<0.001$ \\
\hline $\mathrm{WBC}\left(10^{3} / \mathrm{ml} ;\right.$ mean $\left.\pm \mathrm{SD}\right)$ & $7.3 \pm 2.8$ & $7.3 \pm 1.9$ & $7.5 \pm 1.9$ & $8.3 \pm 2.4$ & $10.2 \pm 3.5$ & $<0.001$ \\
\hline $\mathrm{HbA} 1 \mathrm{c}(\mathrm{mmol} / \mathrm{l} \pm \mathrm{SD})$ & $47.6 \pm 15.4$ & $45.6 \pm 13.7$ & $46.1 \pm 13.1$ & $45.6 \pm 12.7$ & $45.7 \pm 14.7$ & 0.32 \\
\hline HDL cholesterol (mg/dl) & $39.6 \pm 11.1$ & $39.5 \pm 11.2$ & $40.4 \pm 11.6$ & $38.8 \pm 11.5$ & $39.2 \pm 12.1$ & 0.38 \\
\hline Total cholesterol $(\mathrm{mg} / \mathrm{dl} \pm \mathrm{SD})$ & $160.7 \pm 42.3$ & $160.6 \pm 43.4$ & $160.8 \pm 40.2$ & $161.5 \pm 43.8$ & $156.9 \pm 40.7$ & 0.61 \\
\hline Fibrinogen $(\mathrm{mg} / \mathrm{dl} \pm \mathrm{SD})$ & $399 \pm 116$ & $418 \pm 127$ & $420 \pm 117$ & $461 \pm 165$ & $479 \pm 193$ & $<0.001$ \\
\hline C-reactive protein $(\mathrm{mg} / \mathrm{dl} \pm \mathrm{SD})$ & $0.52 \pm 0.1$ & $0.78 \pm 0.19$ & $0.86 \pm 0.2$ & $1.53 \pm 0.15$ & $3 \pm 0.49$ & $<0.001$ \\
\hline
\end{tabular}

trophils, and the subsequent regulatory immune response, involving lymphocytes.

Indeed, neutrophils have been claimed to be responsible for each step leading to acute coronary events and in addition, a low lymphocyte count has also been associated with worse prognosis in patients with ischemic heart disease and unstable angina [27], as a certain subset of lymphocytes has been shown to play an inhibitory role in atherosclerosis, possibly by controlling and regulating the inflammatory response [28].
In fact, NLR has been associated with indirect indicators of atherosclerosis, such as the coronary calcium score, and to the extent of angiographically defined coronary artery disease [8]. Moreover, NLR has emerged as a predictor of clinical outcome in both stable patients undergoing percutaneous or surgical coronary revascularisation [29] and in patients with acute coronary syndrome [30], with the majority of studies conducted in the setting of acute myocardial infarction. In particular, Ergelen et al. reported in a large cohort of STEMI patients that NLR levels $>6.97$ were associated with increased in-hospital and long-term 
Tab. 2 Angiographic and procedural characteristics neutrophil/lymphocyte ratio quintiles

\begin{tabular}{|c|c|c|c|c|c|c|}
\hline Procedural features & $\begin{array}{l}\text { I quintile } \\
n=498\end{array}$ & $\begin{array}{l}\text { II quintile } \\
n=478\end{array}$ & $\begin{array}{l}\text { III quintile } \\
n=490\end{array}$ & $\begin{array}{l}\text { IV quintile } \\
n=461\end{array}$ & $\begin{array}{l}\mathrm{V} \text { quintile } \\
n=461\end{array}$ & $p$ value \\
\hline Severe CAD $(\%)^{\mathrm{a}}$ & 25 & 32 & 32.7 & 28.8 & 37.9 & 0.009 \\
\hline Multivessel disease (\%) & 54.4 & 63 & 56.8 & 56 & 63.7 & 0.17 \\
\hline GP IIb/IIIa inhibitors ${ }^{\text {a }}$ & 44.3 & 43.3 & 39.8 & 47.2 & 43.1 & 0.78 \\
\hline $\begin{array}{l}\text { Clopidogrel bolus }>6 \mathrm{~h} \\
\text { pre-PCI }^{\text {a }}\end{array}$ & 21.5 & 22.4 & 25.7 & 25.7 & 16.5 & 0.1 \\
\hline Multivessel PCI ${ }^{\mathrm{a}}$ & 23.2 & 25.6 & 27.4 & 22.9 & 23.5 & 0.79 \\
\hline Lesion length $(\mathrm{mm} \pm \mathrm{SD})$ & $22 \pm 13.7$ & $20.8 \pm 13.7$ & $21.6 \pm 13.7$ & $21.5 \pm 12.9$ & $21.4 \pm 14.8$ & 0.82 \\
\hline $\begin{array}{l}\text { Target vessel diameter }(\mathrm{mm} \pm \\
\text { SD) }\end{array}$ & $3 \pm 0.6$ & $3 \pm 0.6$ & $3 \pm 0.6$ & $3 \pm 0.6$ & $3 \pm 0.6$ & 0.88 \\
\hline$\%$ Stenosis $( \pm \mathrm{SD})$ & $89.7 \pm 9.5$ & $87.8 \pm 10.2$ & $88.8 \pm 10$ & $90.4 \pm 9.3$ & $90.6 \pm 9.5$ & $<0.001$ \\
\hline Target vessel & & & & & & 0.65 \\
\hline Right coronary artery $(\%)$ & 21 & 18.9 & 22.6 & 22.5 & 20.4 & \\
\hline Left main $(\%)$ & 3 & 2 & 3 & 1.1 & 1.9 & \\
\hline Left anterior descending $(\%)$ & 29.6 & 31.1 & 25.6 & 28.1 & 27.2 & \\
\hline Circumflex branch (\%) & 16.1 & 16 & 16.7 & 13.4 & 16.4 & \\
\hline Saphenous venous graft $(\%)$ & 2.6 & 4.2 & 3 & 2.8 & 2.7 & \\
\hline Anterolateral branch $(\%)$ & 11.1 & 11.8 & 13.2 & 13.4 & 11.6 & \\
\hline Type C lesions (\%) & 31.4 & 25.1 & 29.9 & 32.4 & 33.8 & 0.12 \\
\hline Eccentric plaques (\%) & 97.9 & 98.9 & 97.6 & 98.1 & 97.9 & 0.69 \\
\hline Calcifications (\%) & 10 & 14 & 18.5 & 17.8 & 16.2 & 0.005 \\
\hline Thrombus (\%) & 6.9 & 3.4 & 6.5 & 14.8 & 17.5 & $<0.001$ \\
\hline TIMI flow pre-PCI <3 (\%) & 24.3 & 21.3 & 22.6 & 26.5 & 33.2 & $<0.001$ \\
\hline In-stent restenosis $(\%)$ & 8.2 & 8 & 5.5 & 5.1 & 5.5 & 0.04 \\
\hline Chronic occlusion (\%) & 7.9 & 6.6 & 9.4 & 7.1 & 6 & 0.42 \\
\hline Bifurcations (\%) & 23.9 & 26.6 & 28.1 & 20.6 & 20.4 & 0.06 \\
\hline Pre-dilatation (\%) & 64.9 & 64.4 & 62.1 & 72.7 & 64.6 & 0.32 \\
\hline Direct stenting (\%) & 28.5 & 28 & 28.7 & 20.5 & 27.8 & 0.18 \\
\hline Drug-eluting stents (\%) & 71.2 & 65.7 & 65.8 & 62.4 & 59.9 & 0.001 \\
\hline Max inflation $(\operatorname{atm} \pm \mathrm{SD})$ & $21.6 \pm 3.7$ & $21 \pm 3.5$ & $20.9 \pm 4.1$ & $20.7 \pm 3.6$ & $21 \pm 3.4$ & 0.06 \\
\hline Kissing balloon $(\%)$ & 18.2 & 14.3 & 16.6 & 14.6 & 11.6 & 0.05 \\
\hline Thrombectomy (\%) & 2.1 & 1.7 & 2.4 & 3.6 & 7.4 & $<0.001$ \\
\hline TIMI post $\mathrm{PCI}<3(\%)$ & 20.8 & 21.8 & 19.3 & 22.5 & 26.7 & 0.003 \\
\hline Any dissection (\%) & 1.3 & 1.4 & 1.8 & 1.1 & 0.6 & 0.35 \\
\hline Slow flow (\%) & 2.6 & 1.4 & 1.5 & 2.2 & 4.2 & 0.12 \\
\hline Coronary perforation (\%) & 1.3 & 2.2 & 0.8 & 1.1 & 0.8 & 0.27 \\
\hline Distal embolisation (\%) & 1 & 0.6 & 1.5 & 1.4 & 2 & 0.16 \\
\hline Additional stent required (\%) & 1 & 1.1 & 2.2 & 1.6 & 2 & 0.24 \\
\hline Side branch loss $(\%)$ & 0.8 & 0.8 & 0.7 & 1.1 & 0 & 0.36 \\
\hline
\end{tabular}

aPer patient definition

cardiovascular mortality, and similar results were reported in a Korean population of patients undergoing primary PCI $[11,31]$. However, so far few studies have evaluated the role of NLR in patients undergoing elective percutaneous coronary revascularisation.

In our study we observed a relevant impact of elevated NLR on periprocedural MI in a large population of patients undergoing elective PCI, as all acute patients underwent pharmacological stabilisation before coronary angiography. Indeed, confirming previous findings, higher
NLR has been associated with acute coronary syndrome, intracoronary thrombus and other inflammatory parameters, such as C-reactive protein and fibrinogen; however, our positive association between NLR and periprocedural MI was maintained at multivariate analysis even after correction for potential confounders. Moreover, using the ROC curve we identified NLR $\geq 3$ as being best for predicting the risk of periprocedural MI.

Similar results were obtained by Akpet and colleagues, although in a population of STEMI patients, reporting that 
an NLR > 3.3 had a $74 \%$ specificity and $83 \%$ sensitivity to predict the phenomenon of no-reflow [32], an event that has been associated to a larger infarct size and a worse prognosis in patients undergoing primary PCI.

Analogous results were reported by Soylu et al. linking NLR to the no-reflow development in patients undergoing primary PCI [33]. In addition, Yilmaz et al. identified a significant association between this inflammatory marker and the presence of intracoronary thrombus [10], which has been demonstrated to increase the risk of distal embolisation and impaired myocardial perfusion in patients undergoing PCI. In this context, the extensive use of potent antiplatelet drugs, such as abciximab and other GP IIb/ IIIa inhibitors in our patients, could have influenced thrombus burden and then prevented a large number of events, although no difference in administration of GP IIb/IIIa inhibitors was observed across the NLR quintiles.

Therefore, future studies are certainly needed to evaluate whether lowering NLR can prevent periprocedural myocardial injury after PCI and whether these effects can contribute to the myocardial protection proposed for certain drugs, such as for acetylsalicylic acid and especially for statins $[34,35]$. In fact, in our study they were significantly inversely related to NLR, an association that can be explained by the pleiotropic, anti-inflammatory effects of statins, rather than their hypolipaemic effect.

\section{Study limitations}

A first limitation to our study can be considered the inclusion of a cohort of patients who were heterogeneous for certain clinical baseline characteristics, including risk factors as older age, hyperglycaemia, acute presentation or previous revascularisation, which are known per se to influence the occurrence of periprocedural MI. We observed a relatively high rate of periprocedural MI, which could be explained by the large number of complex, high-risk patients, including those with acute coronary syndrome. The lower rate of events among stable patients could have contributed to the lack of significance of the association between NLR and periprocedural MI in this context.

However, the aim of the present study was to assess the impact of NLR in a real-life population of patients undergoing PCI and in addition, the independent relationship of NLR and periprocedural MI was confirmed even after correction for potential confounders. Even though the greatest increase in periprocedural MI was observed in patients with NLR in the IV and V quintiles, especially for values above 3 , as identified by the ROC curve analysis, no linear relationship was observed between NLR and periprocedural MI. Nevertheless, the association for this parameter with
NLR was quite weak, and certainly its impact in clinical practice needs further confirmation.

In fact, we did not collect data from long-term followup in our patients and therefore we cannot evaluate the long-term prognostic impact of periprocedural myonecrosis and effects of NLR on outcome after stent implantation. However, it has been advocated that periprocedural MI is probably only of minor relevance for patient prognosis, and especially for troponin elevation. The frequent increase in troponin after PCI could have potentially masked the relationship with NLR, thus rendering its determination nonspecific.

In addition, we did not evaluate NLR changes after PCI, although very modest changes in these parameters are usually observed in elective patients; this in contrast to STEMI patients where the leukocyte profile at 24 hours after primary PCI, but not the baseline haematological indexes, has been demonstrated to be an independent predictor of cardiovascular outcome [8].

Finally, the use of intravascular imaging, as intravascular ultrasound or optical coherence tomography, would certainly have prevented periprocedural complications in patients with suboptimal procedural results after coronary stent implantation.

\section{Conclusions}

The present study is the first to demonstrate that in patients undergoing non-urgent PCI a higher NLR increases the risk of periprocedural myocardial infarction, especially for values $\geq 3$.

Funding The authors declare no funding sources.

Conflict of interest M. Verdoia, A. Schaffer, L. Barbieri, G. DiGiovine, G. Bellomo, P. Marino, H. Suryapranata and G. DeLuca state that there are no conflicts of interest.

Open Access This article is distributed under the terms of the Creative Commons Attribution 4.0 International License (http:// creativecommons.org/licenses/by/4.0/), which permits unrestricted use, distribution, and reproduction in any medium, provided you give appropriate credit to the original author(s) and the source, provide a link to the Creative Commons license, and indicate if changes were made.

\section{References}

1. Navarese EP, Luca G de, Castriota F, et al. Low-molecular-weight heparins vs. unfractionated heparin in the setting of percutaneous coronary intervention for ST-elevation myocardial infarction: a meta-analysis. J Thromb Haemost. 2011;9:1902-1915.

2. Luca G de, Smit JJ, Ernst N, et al. Impact of adjunctive tirofiban administration on myocardial perfusion and mortality in patients undergoing primary angioplasty for ST-segment elevation myocardial infarction. Thromb Haemost. 2005;93:820-823. 
3. Capozzolo C, Piscione F, Luca G de, et al. Direct coronary stenting: effect on coronary blood flow, immediate and late clinical results. Catheter Cardiovasc Interv. 2001;53:464-473.

4. Cuculi F, Lim CC, Banning AP. Periprocedural myocardial injury during elective coronary intervention: is it important and how can it be prevented? Heart. 2010;96:736-740.

5. Hanna EB, Hennebry TA. Periprocedural myocardial infarction: review and classification. Clin Cardiol. 2010;33:476-483.

6. Michaels AD, Gibson CM, Barron HV. Microvascular dysfunction in acute myocardial infarction: focus on the roles of platelet and inflammatory mediators in the no-reflow phenomenon. Am J Cardiol. 2000;85:50b-60b.

7. Shah N, Parikh V, Patel N, et al. Neutrophil lymphocyte ratio significantly improves the Framingham risk score in prediction of coronary heart disease mortality: Insights from the National Health and Nutrition Examination Survey-III. Int J Cardiol. 2014;171:390-397.

8. Park BJ, Shim JY, Lee HR, et al. Relationship of neutrophil-lymphocyte ratio with arterial stiffness and coronary calcium score. Clin Chim Acta. 2011;412:925-929.

9. Fowler AJ, Agha RA. Neutrophil/lymphocyte ratio is related to the severity of coronary artery disease and clinical outcome in patients undergoing angiography - the growing versatility of NLR. Atherosclerosis. 2013;228:44-45.

10. Yilmaz M, Tenekecioglu E, Arslan B, et al. White Blood Cell Subtypes and Neutrophil-Lymphocyte Ratio in Prediction of Coronary Thrombus Formation in Non-ST-Segment Elevated Acute Coronary Syndrome. Clin Appl Thromb Hemost. 2015;21:446-452.

11. Sawant AC, Adhikari P, Narra SR, et al. Neutrophil to lymphocyte ratio predicts short and long term mortality following revascularization therapy for ST elevation myocardial infarction. Cardiol J. 2014;21:500-508.

12. Han YC, Yang TH, Kim DI, et al. Neutrophil to Lymphocyte Ratio Predicts Long-Term Clinical Outcomes in Patients with ST-Segment Elevation Myocardial Infarction Undergoing Primary Percutaneous Coronary Intervention. Korean Circ J. 2013;43:93-99.

13. Luca G de, Santagostino M, Secco GG, et al. Mean platelet volume and the extent of coronary artery disease: results from a large prospective study. Atherosclerosis. 2009;206:292-297.

14. Luca G de, Secco GG, Santagostino M, et al. Novara Atherosclerosis Study Group (NAS). Uric acid does not affect the prevalence and extent of coronary artery disease. Results from a prospective study. Nutr Metab Cardiovasc Dis. 2012;22:426-433.

15. Luca G de, Cassetti E, Verdoia M, Marino P. Bivalirudin as compared to unfractionated heparin among patients undergoing coronary angioplasty: A meta-analyis of randomised trials. Thromb Haemost. 2009;102:428-436.

16. Postma S, Dambrink JH, Boer MJ de, et al. The influence of residential distance on time to treatment in ST-elevation myocardial infarction patients. Neth Heart J. 2014;22:513-519.

17. Luca G de, Ernst N, van't Hof AW, et al. Predictors and clinical implications of early reinfarction after primary angioplasty for ST-segment elevation myocardial infarction. Am Heart J. 2006;151:1256-1259.

18. Luca G de, Małek LA, Maciejewski P, et al. STEMI 2003 Registry Collaborators. Impact of diabetes on survival in patients with STsegment elevation myocardial infarction treated by primary angioplasty: insights from the POLISH STEMI registry. Atherosclerosis. 2010;210:516-520.

19. Luca G de, Gibson CM, Bellandi F, et al. Diabetes mellitus is associated with distal embolization, impaired myocardial perfusion, and higher mortality in patients with ST-segment elevation myocardial infarction treated with primary angioplasty and glycoprotein IIb-IIIa inhibitors. Atherosclerosis. 2009;207:181-185.
20. Luca G de, Ernst N, Suryapranata H, et al. Relation of interhospital delay and mortality in patients with ST-segment elevation myocardial infarction transferred for primary coronary angioplasty. Am J Cardiol. 2005;95:1361-1363.

21. Rasoul S, Ommen V van, Vainer J, et al. Multivessel revascularisation versus infarct-related artery only revascularisation during the index primary PCI in STEMI patients with multivessel disease: a meta-analysis. Neth Heart J. 2015;23:224-231.

22. Selvanayagam JB, Porto I, Channon K, et al. Troponin elevation after percutaneous coronary intervention directly represents the extent of irreversible myocardial injury: insights from cardiovascular magnetic resonance imaging. Circulation. 2005; 111:1027-1032.

23. Mach F, Schonbeck U, Bonnefoy JY, Pober JS, Libby P. Activation of monocyte/macrophage functions related to acute atheroma complication by ligation of CD40: induction of collagenase, stromelysin, and tissue factor. Circulation. 1997;96:396-399.

24. Becatti M, Fiorillo C, Gori AM, et al. Platelet and leukocyte ROS production and lipoperoxidation are associated with high platelet reactivity in Non-ST elevation myocardial infarction (NSTEMI) patients on dual antiplatelet treatment. Atherosclerosis. 2013;231:392-400.

25. Wang TJ. Assessing the role of circulating, genetic, and imaging biomarkers in cardiovascular risk prediction. Circulation. 2011;123:551-565.

26. Prasad A, Stone GW, Stuckey TD, et al. Relation between leucocyte count, myonecrosis, myocardial perfusion, and outcomes following primary angioplasty. Am J Cardiol. 2007;99:1067-1071.

27. Husser O, Bodi V, Sanchis J, et al. White blood cell subtypes after STEMI: temporal evolution, association with cardiovascular magnetic resonance-derived infarct size and impact on outcome. Inflammation. 2011;34:73-84.

28. Cantor H, Simpson E. Regulation of the immune response by subclasses of T lymphocytes. I. Interactions between pre-killer T cells and regulatory $\mathrm{T}$ cells obtained from peripheral lymphoid tissues of mice. Eur J Immunol. 1975;5:330-336.

29. Duffy BK, Gurm HS, Rajagopal V, et al. Usefulness of an elevated neutrophil to lymphocyte ratio in predicting long-term mortality after percutaneous coronary intervention. Am J Cardiol. 2006;97:993-996.

30. Tamhane UU, Aneja S, Montgomery D, et al. Association between admission neutrophil to lymphocyte ratio and outcomes in patients with acute coronary syndrome. Am J Cardiol. 2008;102:653-657.

31. Ergelen M, Uyarel H, Altay S, et al. Predictive Value of Elevated Neutrophil to Lymphocyte Ratio in Patients Undergoing Primary Angioplasty for ST-Segment Elevation Myocardial Infarction. Clin Appl Thromb Hemost. 2014;20:427-432.

32. Akpek M, Kaya MG, Lam YY, et al. Relation of neutrophil/ lymphocyte ratio to coronary flow to in-hospital major adverse cardiac events in patients with ST-elevated myocardial infarction undergoing primary coronary intervention. Am J Cardiol. 2012;110:621-627.

33. Soylu K, Yuksel S, Gulel O, et al. The relationship of coronary flow to neutrophil/lymphocyte ratio in patients undergoing primary percutaneous coronary intervention. J Thorac Dis. 2013;5:258-264.

34. Sardella G, Lucisano L, Mancone M, et al. Comparison of high reloading ROsuvastatin and Atorvastatin pretreatment in patients undergoing elective PCI to reduce the incidence of MyocArdial periprocedural necrosis. The ROMA II trial. Int J Cardiol. 2013;168:3715-3720.

35. Leoncini M, Toso A, Maioli M, et al. Early high-dose rosuvastatin and cardioprotection in the protective effect of rosuvastatin and antiplatelet therapy on contrast-induced acute kidney injury and myocardial damage in patients with acute coronary syndrome (PRATO-ACS) study. Am Heart J. 2014;168:792-797. 


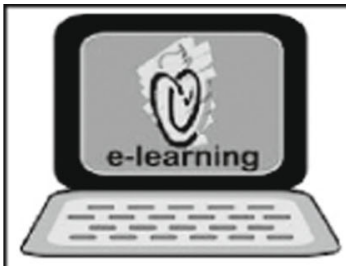

\section{CVOI E-learning formula!}

This is the CVOI e-learning article. The author has prepared 10 questions which are available through the website of the Cardiovascular Educational Institute (CVOI). Please follow the instructions below.

After finishing the questions you will be asked to fill in your name, hospital and e-mail address; then press the button 'verzenden'.

When 6 out of the 10 questions are answered correctly, you acquire 1 accreditation point granted by the Quality Committee of the Netherlands Society of Cardiology (NVVC). The acquired point will be credited to your personal file in the GAIA system. You will also receive an e-mail with all the correct answers.

Over a period of one year 10 e-learning articles will appear in 10 subsequent NHJ editions. In each edition the e-learning article will be recognisable by a special icon. On an annual basis you can collect 10 accreditation points. The accreditation points are credited in the GAIA system by the CVOI.

If you need additional information, please contact the CVOI by e-mail: cvoi@cvoi.org or by phone: 030-2345001.

E.E. van der Wall

Chief editor NHJ
K.B. Schick

Coordinator CVOI 